\title{
Tempo de secagem e da atividade de óxido-redutases de yacon (Smallanthus sonchifolius) sob tratamento químico
}

\author{
Drying time and yacon (Smallanthus sonchifolius) enzymatic activity inhibition \\ under chemical treatment
}

\author{
Vivianne Montarroyos Padilha'* Priscilla Moura Rolim ${ }^{I}$ Silvana Magalhães Salgado ${ }^{\mathrm{I}}$ \\ Alda Verônica Souza Livera' ${ }^{\mathrm{I}}$ Michelle Galindo de Oliveira ${ }^{\mathrm{I}}$
}

\section{RESUMO}

Evidências científicas reconhecem o yacon (Smallanthus sonchifolius) como fonte promissora de frutanos, tais como inulina e frutooligossacarídeos (FOS). No entanto, a presença de compostos fenólicos torna-o suscetível à reação de escurecimento enzimático. Este trabalho teve como objetivo avaliar o emprego de agentes químicos no processamento de yacon, para obtenção de farinha, a fim de inibir o escurecimento enzimático do produto e favorecer o tempo de secagem. Amostras de yacon sem inibição química, de yacon submetido à solução de cloreto de cálcio $1,0 \mathrm{~g} 100 \mathrm{~g}^{-1}$ por 30 minutos e de yacon submetido à solução de metabissulfito de potássio $0,5 \mathrm{~g}$ $100 g^{-1}$ por 5 minutos foram secas a $55^{\circ} \mathrm{C}$, em estufa ventilada, e o teor de água e curvas de secagem foram determinados. As atividades das enzimas peroxidase (POD) e polifenoloxidase (PPO) foram determinadas antes e após a secagem como um possível marcador bioquímico do escurecimento enzimático desse tubérculo. No parâmetro umidade, os três tratamentos apresentaram-se semelhantes; porém, o tratamento 2 (cloreto de cálcio) reduziu a umidade no menor tempo. Antes e após o tratamento térmico, a atividade enzimática foi maior no tratamento 3 (metabissulfito de potássio). As atividades enzimáticas não foram inativadas completamente pela ação térmica. Para a obtenção da farinha de yacon, o tratamento com cloreto de cálcio $1,0 \mathrm{~g} 100 \mathrm{~g}^{-1}$ por 30 minutos foi o que apresentou melhor resultado. Apesar de não inibir totalmente a atividade das enzimas POD e PPO foi o melhor tratamento de inativação, propiciando menor tempo de secagem e melhor firmeza da matéria-prima e facilitando o processamento para obtenção da farinha.

Palavras-chave: peroxidase, polifenoloxidase, curva de secagem, cloreto de cálcio, metabissulfito de potássio.

\section{ABSTRACT}

Scientific evidences acknowledged the yacon (Smallanthus sonchifolius) like a promise source of fructans, as inulin and fructooligosaccharides - FOS, meanwhile, the presence of phenolic coumpounds became this susceptible to enzimatic browning reaction. This project aimed to evaluate the use of chemical agents in yacon processing to obtain flour in a way that inhibits enzymatic darkening of the product besides determining the enzymatic activity in these treatments. Samples of yacon without chemical inhibitions, yacon treated with $1.0 \mathrm{~g}$ $100 g^{-1}$ calcium chloride for 30 seconds and yacon treated with

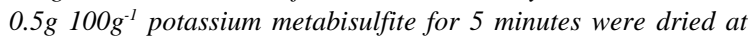
$55^{\circ} \mathrm{C}$ in a ventilated greenhouse and the proportions of humidity and drying curves were determined. The peroxidase activities and polyphenol oxidase enzymes were checked before and after being dried with an enzymatic darkening possible biochemist marker of this tubercle. Regarding humidity Parameter all the three treatment were equivalent, but treatment 2 (calcium chloride) reduced the humidity in lower time. Before and after the thermal treatment the enzymatic activity was higher in treatment 3 (potassium metabisulfite). The thermal action did not inhibit completely polyphenol oxidase and peroxidase. The treatment with calcium chloride at $1.0 \mathrm{~g} 100 \mathrm{~g}^{-1}$ for 30 minutes to obtain yacon flour was the one with better result despite the fact that it did not inhibit completely peroxidase and polyphenol oxidase enzymes activity, offering a better drying time better material of row firmness, facilitating the process for obtaining the meal.

Key words: peroxidase, polyphenoloxidase, drying curve, calcium chloride, potassium metabisulfite.

\section{INTRODUÇÃO}

Evidências científicas reconhecem o yacon (Smallanthus sonchifolius) como fonte promissora de frutanos, tais como inulina e frutooligossacarídeosFOS, fibra alimentar com função prebiótica, proporcionando inúmeros benefícios à saúde humana.

'Laboratório de Experimentação e Análise de Alimentos Prof. Nonete Guerra (LEAAL), Universidade Federal de Pernambuco (UFPE), 50670-901, Recife, PE, Brasil. E-mail: vivianne_padilha@yahoo.com.br. *Autor para correspondência. 
Além disso, o yacon possui aplicação tecnológica no desenvolvimento de novos produtos alimentícios (MOSCATTO et al., 2006; MALDONADO et al., 2008; SANTANA et al., 2008).

A presença de compostos fenólicos, como o ácido clorogênico, e do aminoácido L-triptofano torna os tubérculos do yacon suscetíveis à reação de escurecimento causada pelas enzimas peroxidase (POD) e polifenoloxidase (PPO). Nessa reação ocorre a formação de melanina (pigmento escuro), que deprecia a qualidade do produto (NEVES et al., 2007). O controle dessa reação pode ser feito por meio da desidratação, do armazenamento em baixas temperaturas, do tratamento térmico, da eliminação do oxigênio do meio, da utilização de agentes químicos, dentre outros (CABELLO, 2005; LUPETTI et al., 2005).

POD induz alterações negativas de sabor durante a estocagem. Ela é capaz de catalisar um grande número de reações oxidativas, usando peróxido de hidrogênio como substrato ou, em alguns casos, oxigênio como aceptor de hidrogênio. É considerada a enzima vegetal mais estável ao calor e sua inativação tem sido usada como indicador de adequação de branqueamento (FREITAS et al., 2008). PPO, por sua vez, promove a oxidação enzimática de compostos fenólicos, produzindo, inicialmente, quinona, que rapidamente se condensa, formando pigmentos insolúveis e escuros, denominados melanina, ou reagem não enzimaticamente com aminoácidos, proteínas ou outros compostos (MENOLLI et al., 2008).

A secagem de produtos é um processo utilizado em vários países, objetivando preservar e/ou inibir a atividade enzimática. Esse processo consiste na remoção de água e substâncias voláteis de um produto sólido, diminuindo assim sua atividade de água (CORRÊA et al., 2007). Considerando os efeitos indesejáveis e a grande importância da inibição das óxido-redutases durante a transformação de matériasprimas para a obtenção de produtos processados, o presente trabalho objetivou avaliar a influência de tratamentos químicos sobre o tempo de secagem e a atividade da POD e da PPO para obtenção de farinha de yacon.

\section{MATERIAL E MÉTODOS}

Preparo das amostras

Tubérculos (400g) de yacon (Smallanthus sonchifolius) obtidos do Centro de Abastecimento (CEASA) da região metropolitana do Recife, Pernambuco (PE), foram submetidos a três tratamentos distintos, conforme fluxograma apresentado na figura 1: amostra 1, controle, sem inibidor químico;, amostra
2, yacon tratado com solução de cloreto de cálcio a 1,0g $100 \mathrm{~g}^{-1}$ por 30 minutos; e amostra 3, yacon tratado com solução de metabissulfito de potássio $0,5 \mathrm{~g} 100 \mathrm{~g}^{-1}$ por cinco minutos.

\section{Determinação tempo de secagem}

Os ensaios foram conduzidos em triplicata, e o tempo de secagem foi determinado por gravimetria, a $105^{\circ} \mathrm{C}$ (método 925.10 da AOAC 2002), considerando para encerramento da operação o teor de água requerido, conforme a legislação vigente (BRASIL, 2005), que estabelece valor $\leq 15 \mathrm{~g} 100 \mathrm{~g}^{-1}$ para farináceos.

Determinação da atividade enzimática

Alíquotas de 0,5g da amostra, no tempo zero e após a obtenção das farinhas, com 24 horas de secagem (Figura 2), foram homogeneizadas com tampão fosfato de sódio a 0,05M (pH 6,0), em liquidificador. Em seguida, foram submetidas à centrifugação (8.000rpm, 10 minutos, $5^{\circ} \mathrm{C}$ ). O sobrenadante obtido foi utilizado como extrato enzimático.

A determinação das atividades da PPO e POD foi efetuada de acordo com KHAN \& ROBINSON (1994) e ALMEIDA et al. (1995), respectivamente. Uma unidade de atividade enzimática foi definida como o correspondente à variação de uma unidade de absorbância por minuto $\mathrm{mL}^{-1}$ de amostra. A atividade das enzimas correspondeu à inclinação da reta obtida por meio do gráfico tempo (s) x absorbância (nm).

\section{Análise estatística}

Os resultados foram tratados por análise de variância (ANOVA) e teste de Tukey, a 5\% de significância. Também foi realizada regressão linear entre o tempo de secagem (horas) e a umidade (\%), por meio do programa Statistica for Windows 6.0 (STATSOFT, 2001).

\section{RESULTADOS E DISCUSSÃO}

Na tabela 1, são apresentados os resultados referentes à umidade durante a secagem do yacon em diferentes tratamentos. Os valores obtidos no tempo zero corroboram outras pesquisas, nas quais o yacon apresentou umidade de $80 \%$ a 90\% (SILVA, 2007; LACHMAN et al., 2004; GRAEFE et al., 2004).

Por meio da análise estatística, pode-se perceber que os valores de umidade, em cada tempo de secagem, apresentaram diferenças significativas $(\mathrm{P} \leq 0,05)$, exceto no tempo 0 e para o yacon sem inibidor químico e com tratamento com cloreto de cálcio, sobretudo após seis, 10 e 14 horas de secagem. 


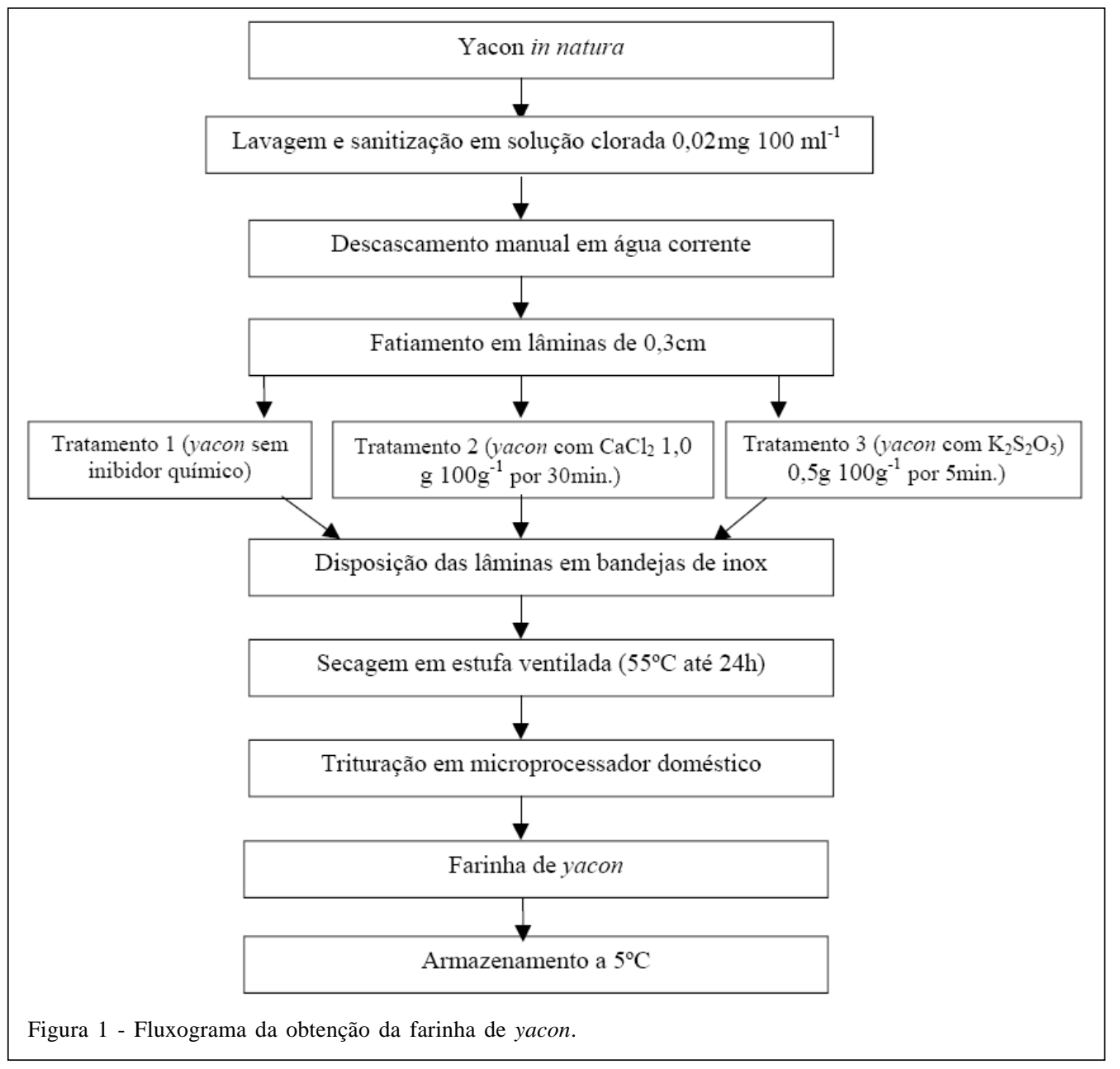

Após 14 horas de secagem, pode-se notar redução brusca nos valores de umidade, fato não evidenciado no tratamento 3 (metabissulfito de potássio), o qual só apresentou redução significativa após 22 horas de secagem. Entretanto, é importante notar que, após 18 horas, a redução foi igual ou superior a 50\%, apresentando também uma redução bastante significativa. Os tratamentos 1 e 2, a partir das 14 horas, apresentam tendência ao equilíbrio nos valores de umidade. Em contrapartida o yacon submetido ao tratamento 3 ainda apresentava umidade muito superior à dos demais tratamentos, possivelmente pelo metabissulfito diminuir a desorção de água do produto.

Outros estudos utilizando metabissulfito de potássio em frutas e hortaliças obtiveram efeitos satisfatórios no que diz respeito à secagem da matériaprima. No presente estudo, o efeito indesejável desse agente químico pode estar relacionado a comportamentos bioquímicos ainda desconhecidos no yacon (NOGUEIRA et al., 2003; OLIVEIRA et al., 2006).
O tratamento 2 (cloreto de cálcio) apresentou um tempo de secagem final menor (14 horas), o que beneficia o aspecto da amostra, deixandoa mais firme (aspecto verificado por meio da sensação tátil) e facilitando o processo de obtenção da farinha. Isso se deve ao fato de que o cloreto de cálcio, por se tratar de um sal, promove uma competição entre os tecidos do vegetal e os íons salinos pela molécula de água, o que consequentemente leva à remoção da água do produto, provocando a coaptação dos tecidos (ARAÚJO, 2004; LINHARES et al., 2007).

Convém destacar que, entre 16 e 20 horas de secagem, no yacon sem inibidor químico, e no período de 14 para 16 horas e 18 para 22 horas, no yacon com cloreto de cálcio (Tabela 1), percebe-se um aumento na umidade das amostras, fato possivelmente explicado por questões de distribuição das lâminas de yacon nas bandejas de inox.

Nas figuras 2 e 3, pode-se observar que as atividades das enzimas oxido-redutases diminuíram 


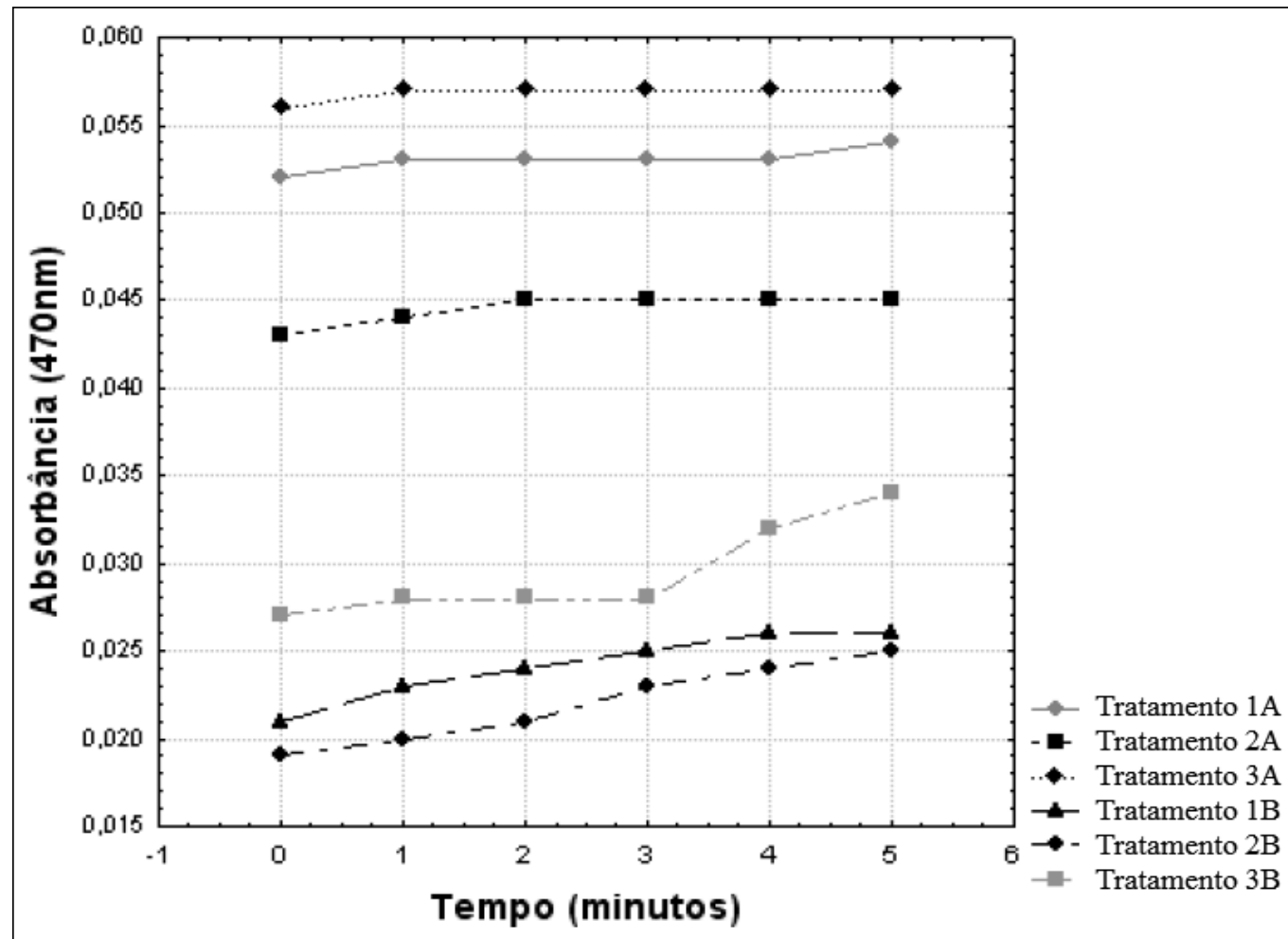

Figura 2 - Atividade da POD nos extratos de yacon antes e após secagem. Tratamento 1A: (sem inibidor químico) antes da secagem; Tratamento $2 \mathrm{~A}: \mathrm{CaCl}_{2} 1,0 \mathrm{~g} 100 \mathrm{~g}^{-1}$ antes da secagem e Tratamento $3 \mathrm{~A}: \mathrm{K}_{2} \mathrm{~S}_{2} \mathrm{O}_{5} 0$,5g $100 \mathrm{~g}^{-1}$ antes da secagem; Tratamento $1 \mathrm{~B}$ : (sem inibidor químico) após secagem; Tratamento $2 \mathrm{~B}$ : $\mathrm{CaCl}_{2}$ 1,0g $100 \mathrm{~g}^{-1}$ após secagem e Tratamento 3B: $\mathrm{K}_{2} \mathrm{~S}_{2} \mathrm{O}_{5} 0,5 \mathrm{~g} 100 \mathrm{~g}^{-1}$ após secagem.

após o tratamento térmico. Com relação à enzima POD, no tratamento com metabissulfito de potássio, houve um aumento da sua atividade após três minutos, evidenciando o poder de regeneração dessa enzima.
Enquanto que, nos tratamentos de controle e com o cloreto de cálcio, houve redução da atividade enzimática, sendo mais expressiva no tratamento com cloreto de cálcio.

Tabela 1 - Valores médios ${ }^{1}$ e desvio padrão do teor de água da farinha de yacon durante a secagem por até 24 horas, em função do tratamento com inibidor de atividade enzimática.

\begin{tabular}{|c|c|c|c|}
\hline \multirow{2}{*}{ Tempo (horas) } & \multicolumn{3}{|c|}{ 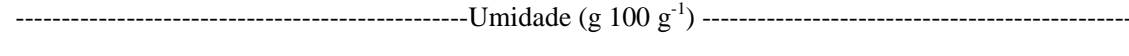 } \\
\hline & Tratamento 1 (sem inibidor) & Tratamento $2\left(\mathrm{CaCl}_{2}\right)$ & Tratamento $3\left(\mathrm{~K}_{2} \mathrm{~S}_{2} \mathrm{O}_{5}\right)$ \\
\hline 0 & $87,5 \pm 1,3 a$ & $90,3 \pm 0,73 a$ & $90,4 \pm 0,42 a$ \\
\hline 2 & $76,0 \pm 0,12 c$ & $87,5 \pm 0,24 b$ & $89,0 \pm 0,38 a$ \\
\hline 4 & $60,3 \pm 1,59 b$ & $84,0 \pm 0,42 a$ & $85,7 \pm 0,98 a$ \\
\hline 6 & $59,2 \pm 0,44 b$ & $61,9 \pm 1,15 b$ & $85,4 \pm 0,12 a$ \\
\hline 8 & $46,6 \pm 1,87 \mathrm{c}$ & $53,3 \pm 0,28 b$ & $77,0 \pm 0,25 a$ \\
\hline 10 & $42,3 \pm 1,29 b$ & $44,8 \pm 1,24 b$ & $74,8 \pm 0,33 a$ \\
\hline 12 & $11,6 \pm 0,30 \mathrm{c}$ & $29,0 \pm 0,72 b$ & $74,9 \pm 0,32 a$ \\
\hline 14 & $8,2 \pm 0,19 b$ & $6,8 \pm 0,43 b$ & $71,8 \pm 0,36 a$ \\
\hline 16 & $6,7 \pm 0,11 b$ & $7,4 \pm 0,35 b$ & $72,2 \pm 0,01 a$ \\
\hline 18 & $6,8 \pm 0,03 b$ & $5,8 \pm 0,01 c$ & $50,5 \pm 0,25 a$ \\
\hline 20 & $8,5 \pm 0,37 b$ & $7,1 \pm 0,27 \mathrm{C}$ & $15,7 \pm 0,17 a$ \\
\hline 22 & $8,6 \pm 0,14 a$ & $7,5 \pm 0,20 \mathrm{~b}$ & $8,6 \pm 0,16 a$ \\
\hline
\end{tabular}

${ }^{1}$ Médias seguidas de letras iguais, na horizontal, não diferem significativamente em nível de 5\%, pelo teste de Tukey.

Ciência Rural, v.39, n.7, out, 2009. 


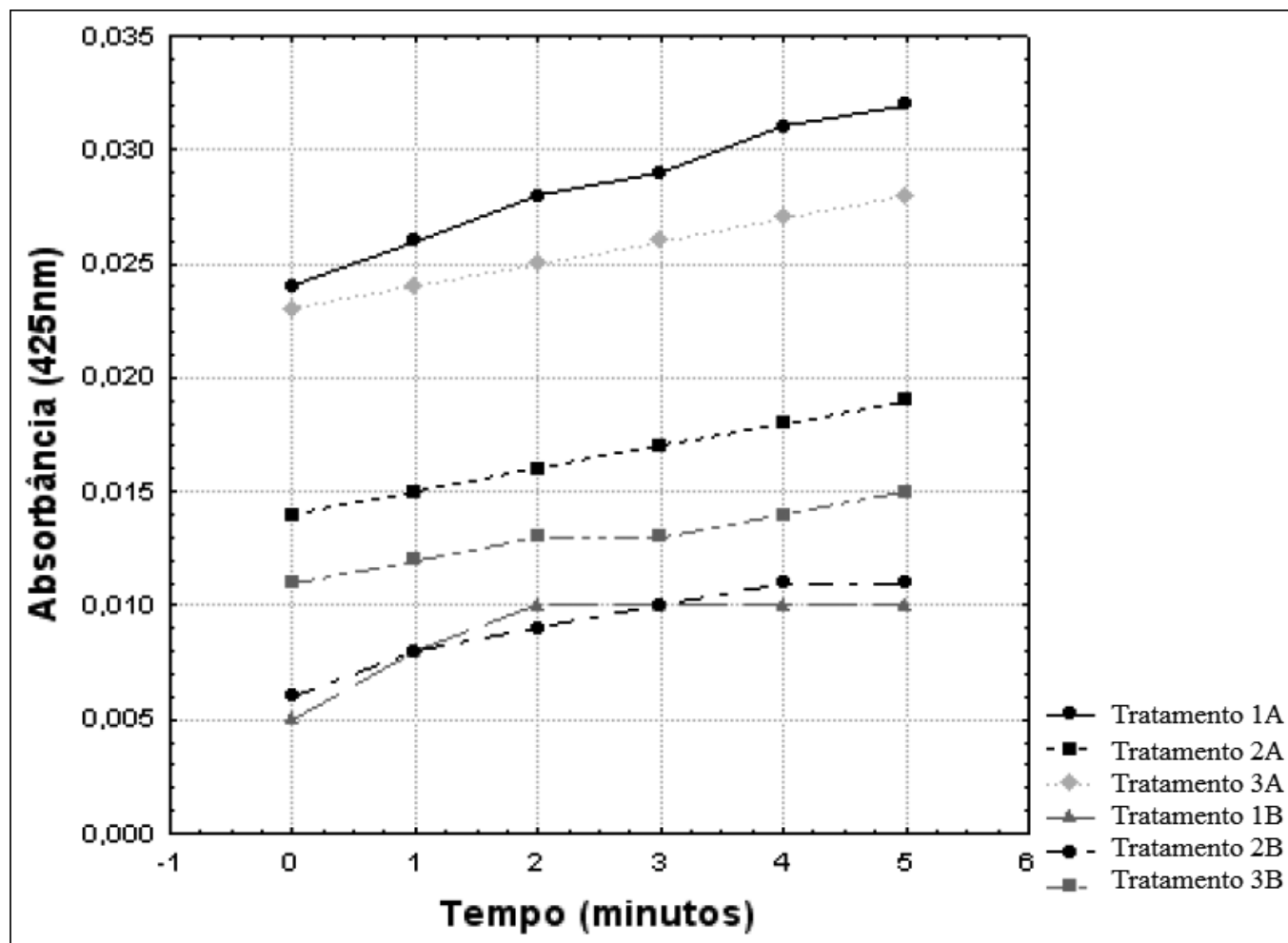

Figura 3 - Atividade da Polifenoloxidase nos extratos de yacon antes e após secagem. Tratamento 1A: (sem inibidor químico) antes da secagem; Tratamento 2A: $\mathrm{CaCl}_{2} 1,0 \mathrm{~g} 100 \mathrm{~g}^{-1}$ antes da secagem; Tratamento 3A: $\mathrm{K}_{2} \mathrm{~S}_{2} \mathrm{O}_{5} 0,5 \mathrm{~g} 100 \mathrm{~g}^{-1}$ antes da secagem; Tratamento 1B: (sem inibidor químico) após secagem; Tratamento 2B: $\mathrm{CaCl}_{2}$ 1,0g $100 \mathrm{~g}^{-1}$ após secagem e Tratamento 3B: $\mathrm{K}_{2} \mathrm{~S}_{2} \mathrm{O}_{5}$ 0,5g $100 \mathrm{~g}^{-1}$ após secagem.

A atividade da PPO apresentou menor após a secagem, demonstrando que o yacon possui maior teor de peroxidase do que polifenoloxidase na polpa, corroborando estudo realizado por RIBEIRO (2008).

Na figura 4, verifica-se que o coeficiente de determinação do modelo para o três tratamentos foi maior que 0,7 , demonstrando boa correlação entre tempo de secagem e umidade. Salienta-se que o tratamento 2 foi o que obteve o melhor ajuste, seguido do tratamento 1.

Com relação à atividade da PPO (Figura 3), pode-se observar que, no tratamento $1 \mathrm{~B}$, a atividade da enzima ficou constante após dois minutos; porém, no tratamento $2 \mathrm{~B}$, a estabilidade só pode ser notada no último minuto da análise. A atividade da polifenoloxidase, após a secagem do yacon, foi maior no tratamento 3B (com metabissulfito de potássio), enquanto que, nos outros dois tratamentos, houve uma tendência à estabilidade.

LAURENTI et al. (2005), no monitoramento térmico da peroxidase em carambola, observaram que a enzima perdia sua atividade com o aumento do tempo e da temperatura. Para o estudo da estabilidade térmica da peroxidase, os extratos brutos foram submetidos a temperaturas de $60,65,70,75,80$ e $85^{\circ} \mathrm{C}$, e a atividade enzimática foi determinada em intervalos de 0, 2, 4, 6, 8 e 10 minutos.

FREITAS et al. (2008), estudando atividade enzimática em geleias e sucos de uva, verificaram maior inativação enzimática a $85^{\circ} \mathrm{C}$ e tempo de exposição de 10 minutos, sendo as operações de cocção e pasteurização mais eficazes nas geleias do que nos sucos. Em contrapartida, a atividade da POD (Figura 2), apesar de significativa redução após a secagem, mostrou-se crescente, destacando-se a amostra com metabissulfito, por apresentar possível regeneração térmica, devido a sua termorresistência (LUIZ et al., 2007).

Em pesquisa semelhante, porém com abacaxis, foi observada regeneração de $10 \%$ da atividade da peroxidase após o tratamento térmico, a $75^{\circ} \mathrm{C}$, não sendo verificado esse efeito em temperatura superior a $90^{\circ} \mathrm{C}$, em estufa (BRITO et al., 2007). Segundo FREITAS et al. (2008), as enzimas podem recuperar suas atividades após a inativação térmica, num processo conhecido como renaturação. É fato conhecido que

Ciência Rural, v.39, n.7, out, 2009. 


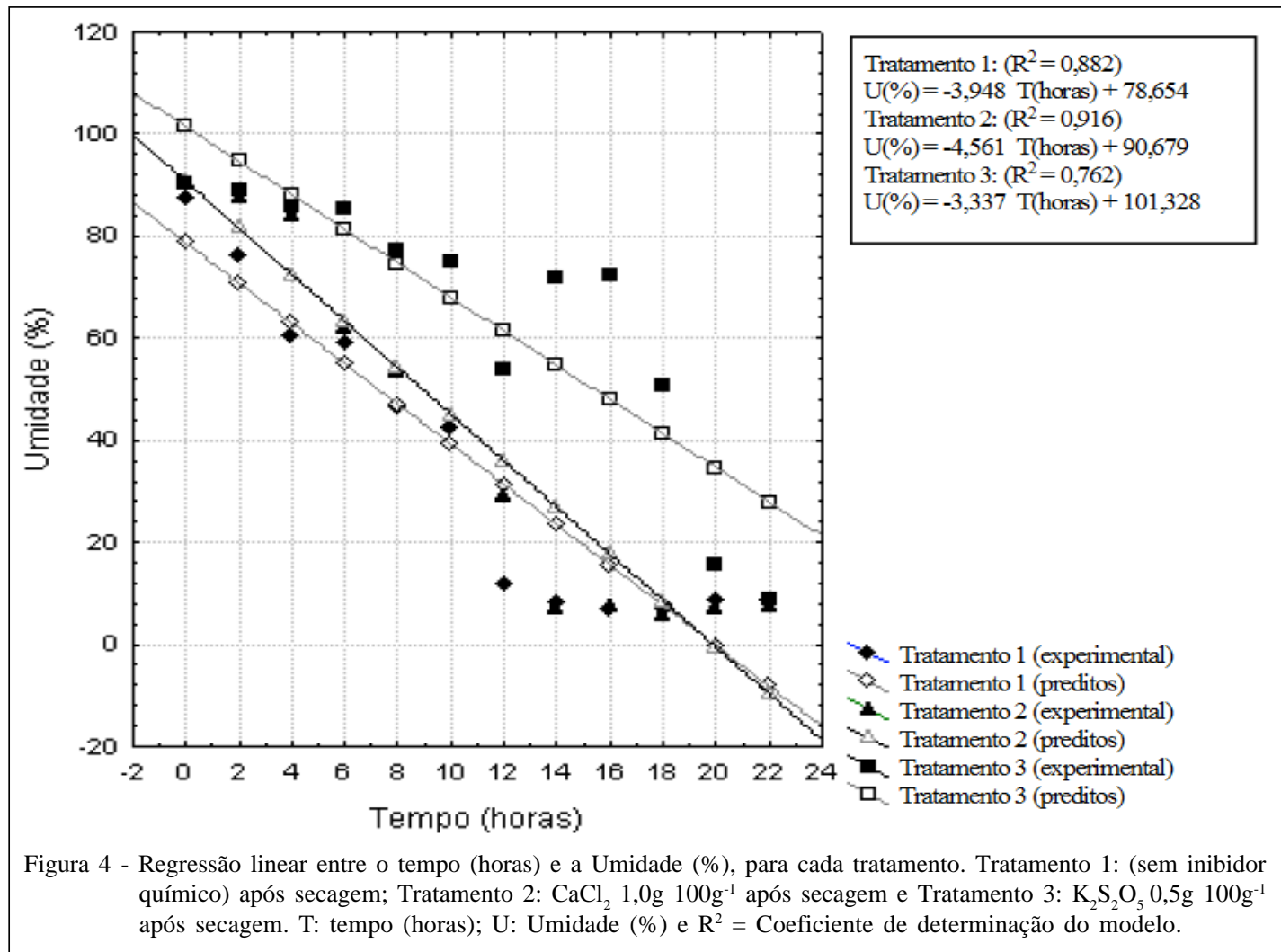

isso é maior quando o resfriamento, que segue o tratamento térmico, é lento, como notado neste trabalho.

Neste contexto, verificou-se que o tratamento 2B (yacon em cloreto de cálcio) diferiu significativamente dos demais ensaios, enfatizando sua maior eficácia na inibição da atividade enzimática. Ao final da secagem, constatou-se que o ensaio utilizando metabissulfito de potássio resultou em dados significativamente distintos dos demais, mostrando efeito contraditório ao esperado, uma vez que o yacon sem inibidor químico apresentou maior inibição da atividade enzimática quando a ele comparado.

\section{CONCLUSÕES}

Para a obtenção de farinha de yacon, o melhor método testado para inativação da POD e PPO a ser utilizado foi o método com solução de cloreto de cálcio a $1,0 \mathrm{~g} 100 \mathrm{~g}^{-1}$ por 30 minutos. Apesar de não inibir totalmente a atividade das enzimas POD e PPO, este propicia ao produto menor tempo de secagem.

\section{REFERÊNCIAS}

ALMEIDA, M.E.M. et al. The control of polyphenol oxidase activity in fruits and vegetables. A study of the iterations between the chemical compounds used and heat treatment. Plant Foods Human Nutrition, Dordrecht, v.47, n.3, p.245-256, 1995.

ARAÚJO, J.M.A. Química de alimentos: teoria e prática. 3ed. Viçosa: UFV, 2004. 465p.

ASSOCIATION OF ANALITICAL CHEMISTS - AOAC. Official methods of analysis of AOAC International. 19.ed. Washington, D.C., 2002. 1219p.

BRASIL. Ministério de Agricultura, Pecuária e Abastecimento. Instrução normativa $n^{\circ}$ 8, 03 jun. 2005. Regulamento Técnico de Identidade e Qualidade da Farinha de Trigo. Diário Oficial da República Federativa do Brasil, Brasília, DF, 03 jun. 2005, Seção 1, n.105, p. 91

BRITO, C.A.K. et al. Abacaxi IAC gomo-de-mel (Ananás comosus (L.) Merril): Características da polpa e da peroxidase do suco. Boletim do CEPPA, Curitiba, v.25, n.2, p.257-266, 2007. Disponível em: <http://www.scielo.br/ scielo.php ? script = sci_art text \& pid = S 0101 20612005000200010>. Acesso em: 14 mai. 2008. doi: 10.1590/S0101-20612005000200010.

CABELLO, C. Extração e pré-tratamento químico de frutanos de yacon, Polymnia sonchifolia. Ciência e Tecnologia de Alimentos, Campinas, v.25, n.2, p.202-207, 2005. Disponível em: <http://www.scielo.br/scielo.php?pid=S0101$20612005000200003 \&$ script $=$ sci_arttext $>$. Acesso em: 08 jan. 2008. doi: 10.1590/S0101-20612005000200003. 
CORRÊA, P.C. et al. Modelagem matemática para a descrição do processo de secagem do feijão (Phaseolus vulgaris L.) em camadas delgadas. Engenharia Agrícola, Jaboticabal, v.27, n.2, p.501-510, 2007. Disponível em: <http://www.scielo.br/scielo.php?pid=S010069162007000300020\&script=sci_arttext>. Acesso em: 15 mar. 2008. doi: 10.1590/S0100-69162007000300020.

FREITAS, A.A.de. et al. Atividades das enzimas peroxidase (POD) e polifenoloxidase (PPO) nas uvas das cultivares benitaka e rubi e em seus sucos e geléias. Ciência e Tecnologia de Alimentos, Campinas, v.28, n.1, p.172-172 177, 2008. Disponível em: /,http://www.scielo.br/scielo.php?pid=S010120612008000100025\&script=sci_arttext $>$. Acesso em: 20 abr. 2008. doi: 10.1590/S0101-20612008000100025.

GRAEFE, S. et al. Effects of post-harvest treatments on the carbohydrate composition of yacon roots in the Peruvian Andes. Field Crops Research, Lima, v.86, p.157-165, 2004.

KHAN, A.A.; ROBINSON, D.S. Hydrogen donor specifity of mango isoperoxidases. Food Chemistry, Londres, v.49, n.4, p.407-410, 1994. Disponível em: <linkinghub.elsevier.com/ retrieve/pii/S0378429003001850>. Acesso em: 04 mai. 2008. doi: 10.1016/j.fcr.2003.08.003.

LACHMAN, L. et al. Saccharides of yacon [Smallanthus sonchifolius (Poepp. et Endl.) H. Robinson] tubers and rhizomes and factors affecting their content. Plant soil environment, Czech Republic, v.50, n.9, p.383-390, 2004.

LAURENTI, C. et al. Avaliação da atividade da peroxidase em carambola (Oxalidacia averrhoa) em diferentes estádios de maturação. Acta Scientiarum Agronomy, Maringá, v.27, n.1, p.159-163. 2005.

LINHARES, L.A. et al. Transformações químicas, físicas e enzimáticas de goiabas 'PEDRO SATO' tratadas na pós-colheita com cloreto de cálcio e 1-metilciclopropeno e armazenadas sob refrigeração. Ciência e Agrotecnologia, Lavras, v.31, n.3, p.829-841, 2007. Disponível em: <http://www.scielo.br/ scielo.php? pid=S $1413-70542007000300033$ \& sc ript=sci_abstract\&tlng=pt $>$. Acesso em: 26 mai. 2008. doi: 10.1590/S1413-70542007000300033.

LUIZ, R.C. et al. Cinética de inativação da polifenoloxidase e peroxidase de abacate (Persea americana Mill.). Ciência e Agrotecnologia, Lavras, v.31, n.1, p.17661773, 2007. Disponível em: <http://www.scielo.br/ s c i e l o.p h p ? s c r i p t = s c i _ a r t t ex t \& p i d $=\mathrm{S} 141370542007000600025 \& \operatorname{lng}=\mathrm{em} \& \mathrm{nrm}=\mathrm{iso} \& \mathrm{t} \operatorname{lng}=\mathrm{em}>$. Acesso em: 17 mar 2008. doi: 10.1590/S141370542007000600025 .

LUPETTI, K.O. et al. Análise de imagem em química analítica: empregando metodologias simples e didáticas para entender e prevenir o escurecimento de tecidos vegetais. Química Nova, São Carlos, v.28, n.3, p.548-554, 2005. Disponível em: <http:/ /www.scielo.br/scielo.php?script=sci_arttext\&pid $>$. Acesso em: 02 jun. 2008. doi: S0100-40422005000300031.

MALDONADO, S. et al. Efecto de gelificantes en la formulación de dulce de yacón. Ciência e Tecnologia de Alimentos,
Campinas, v.28, n.2, p.429-434, 2008. Disponível em: <http:/ / w w w. s c i e l o.b r/ s c i e l o. p h p ? p i d = S 0101 20612008000200025\&script=sci_arttext>. Acesso em: 18 mai. 2008. doi: 10.1590/S0101-20612008000200025.

MENOLLI, L. et al. Atuação das enzimas oxidativas no escurecimento causado pela injúria por frio em raízes de batatabaroa. Acta Scientiarum Agronomy, Maringá, v.30, n.1, p.57-63, 2008. Disponível em: <http://www.periodicos.uem.br/ ojs/index.php/ActaSciAgron/article/viewArticle/1129>. Acesso em: 16 jun. 2008. doi: 10.4025/actasciagron.v30i1.1129.

MOSCATTO, J.A. et al. The optimizacion of the formulation for a chocolate cake containg inulin and yacon meal. Intern. Journal of Food and Technology, Oxford, v.41, p.181-188. 2006. Disponível em: <http://www3.interscience.wiley.com/ journal/118573283/abstract?CRETRY $=1 \&$ SRETRY $=0>$. Acesso em: 19 jun. 2008. doi: 10.1111/j.1365-2621.2005.01047.x

NEVES, V.A. et al. Polyphenoloxidase from Yacon Roots (Smallanthus sonchifolius). Journal of Agricultural and Food Chemistry, Washington, v.55, p.2424-2430, 2007. Disponível em: <http://pubs.acs.org/doi/abs/10.1021/jf063148w>. Acesso em: 13 mai. 2008. doi: 10.1021/jf063148w.

NOGUEIRA, A. et al. Efeito do processamento no teor de compostos fenólicos em suco de maçã. Publicação da Universidade Estadual de Ponta Grossa, Exact Soil Science, Ponta Grossa, v.9, n.3, p.7-14, 2003.

OLIVEIRA, M.C.S. et al. Avaliação do método de liquefação enzimática na extração de suco de maçã. Ciência e Tecnologia de Alimentos, Campinas, v.26, n.4, p.906-915, 2006. Disponível em: $<$ ht t p://www.scielo.br/scielo.php?pid=S 0101 20612006000400030\&script=sci_arttext\&tlng=>. Acesso em: 14 mar. 2008. doi: 10.1590/S0101-20612006000400030.

RIBEIRO, J.A.R. Composição química e aspectos bioquímicos do yacon (Smallanthus sonchifolius) e de suas farinhas. In: Estudo químico e bioquímico do yacon (Smallanthus sonchifolius) in natura e processado e influência do consumo de yacon sobre níveis glicêmicos e lipídeos fecais de ratos. 2008. Cap.2, p.63-98. Dissertação (Mestrado em Ciências dos Alimentos)-Universidade Federal de Lavras, Minas Gerais.

SANTANA, I. et al. Raíz tuberosa de yacon (Smallanthus sonchifolius): potencialidade de cultivo, aspectos tecnológicos e nutricionais. Ciência Rural, Santa Maria, v.38, p.898-905, 2008. Disponível em: <http://www.scielo.br/ scielo.php? s c ript=s ci_art text \& pid = S 0103 84782008000300050>. Acesso em: 12 jun. 2008. doi: $10.1590 /$ S0103-84782008000300050.

SILVA, A.S.S. A raíz da yacon (Smallanthus sonchifollius Poepping \& Endlicher) como fonte de fibras alimentares, sua caracterização físico-química, uso na panificação e sua influência na glicemia pós-prandial. 2007. $156 \mathrm{f}$ Tese (Doutorado em Ciências dos Alimentos) - Universidade Federal de Santa Catarina, Florianópolis.

STATSOFT. Statistic for Windows 6.0. Tulsa, 2001. 76p. 